psychopraxis.neuropraxis $2015 \cdot 18: 28$ DOI 10.1007/s00739-015-0228-3

Online publiziert: 3. Februar 2015

C) Springer-Verlag Wien 2015

Nora Hergovich · Elisabeth Fertl

Neurologische Abteilung, KA Rudolfstiftung, Wien, Österreich

\title{
Erratum zu: Psychose bei hochaktivem MS-Verlauf
}

\section{Eine komplexe neuropsychiatrische Patientin mit großer Lebenslust und wechselhafter Compliance}

\section{Erratum zu:}

psychopraxis.neuropraxis 2014 17:21-23 DOI 10.1007/s00739-014-0215-0

Im Original-Beitrag ist $\bullet$ Tab. 2 leider fehlerhaft. Nachfolgend die Tabelle mit den korrekten Zahlen.

Mit-Autorin Prim. Univ. Doz. Dr. Elisabeth Fertl wurde in der KorrespondenzAdresse leider ohne akademische Titel aufgeführt.

\section{Korrespondenzadressen}

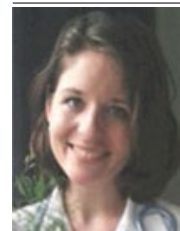

Dr. N. Hergovich

Neurologische Abteilung

KA Rudolfstiftung, Wien

nora.hergovich@wienkav.at

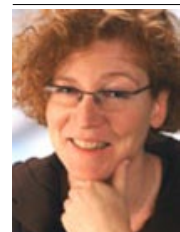

Prim. Univ. Doz. Dr. E. Fertl

Neurologische Abteilung

KA Rudolfstiftung, Wien

\begin{tabular}{|lll|}
\hline $\begin{array}{l}\text { Tab. } 2 \\
\text { kungëvalenz psychiatrischer Erkran- } \\
\text { kungei MS-Patienten im Vergleich zur } \\
\text { gesunden Bevölkerung }\end{array}$ \\
\hline $\begin{array}{l}\text { Psychiatrische } \\
\text { Erkrankung }\end{array}$ & $\begin{array}{l}\text { Gesunde } \\
\text { Bevölke- } \\
\text { rung }\end{array}$ & $\begin{array}{l}\text { MS- Patien- } \\
\text { ten }\end{array}$ \\
\hline $\begin{array}{l}\text { Major Depres- } \\
\text { sion }\end{array}$ & $16,2 \%$ & $36-54 \%$ \\
\hline $\begin{array}{l}\text { Bipolare Stö- } \\
\text { rungen }\end{array}$ & $1-4,5 \%$ & $13 \%$ \\
\hline $\begin{array}{l}\text { Angststörun- } \\
\text { gen }\end{array}$ & $28,8 \%$ & $35,7 \%$ \\
\hline $\begin{array}{l}\text { Anpassungs- } \\
\text { störungen }\end{array}$ & $0,2-2,3 \%$ & $22 \%$ \\
\hline $\begin{array}{l}\text { Psychotische } \\
\text { Störungen }\end{array}$ & $\mathbf{1 , 8} \%$ & $\mathbf{2 - 3} \%$ \\
\hline
\end{tabular}

Tab. 2 Prävalenz psychiatrischer Erkrangesunden Bevölkerung

Die Online-Version des Originalartikels ist unte doi:10.1007/s00739-014-0215-0 zu finden. 